\title{
Identification of Risk Factors for Diabetes Type 2 and Components of Pharmacists' Interventions in Community Pharmacy Setting: A Serbian Pilot Study
}

\author{
Ljiljana Tasić ${ }^{* \star}$ and Vukica Kocić Pešić \\ 1Department of Social Pharmacy and Pharmaceutical Legislation, Faculty of Pharmacy, University of Belgrade, Belgrade, Serbia. \\ ${ }^{2}$ Department of Research and Quality, ADOC company, Belgrade, Serbia.
}

\begin{abstract}
Prevention of Type 2 diabetes (T2D) is clinical service useful to implement on community pharmacy settings (CP). The objectives of study were: to determine the risk factors for T2D in adults visiting a community pharmacy; to determine and describe component of pharmacists' interventions (PI) focusing on feasibility of complex intervention $(\mathrm{Cl})$. A cross-sectional study design and conducted (January 2010 to June 2011) on 20 CP in Serbia. Adult population was enrolled (304 patients). The pharmacist trained for implementation of complex PI (screening and counseling session). The national Questionnaire for T2D risk estimation was used for screening and Intervention check list was design and used for process of counseling. The DEPICT (Descriptive Elements of Pharmacist Intervention Characterization Tool) was used to describe the component of $\mathrm{Cl}$. High and very high risk score was estimated in age group 45-54 (10.80\%) forward in age group 55-64 (9.60\%); into the cohort below 45 year the 59 adults has low T2D risk score. The average value of PI/per patients was 4.02 . From the eight domain/component (operational descriptor in DEPICT) the main component are 'education and counseling' with four type (items) of intervention performed in counseling session. As a conclusion, the pharmacists in CP detected and scoring risk of T2D in Serbian adults' population. The number and type of PI in counseling session adequate to participants clinical profile. Feasibility of the $\mathrm{Cl}$ within the $\mathrm{CP}$ in Serbia was proved. For the outcomes measurements and impact of PI, a proper endpoint and follow-up study design should be conduct.
\end{abstract}

Key words: Prevention, Type 2 Diabetes Mellitus, Pharmacists' Intervention, Complex intervention, Community Pharmacy.

\section{INTRODUCTION}

Diabetes is one of the leading causes of death and disability worldwide, with over 220 million people affected. It contributes to $5 \%$ of all deaths globally and is anticipated to increase by more than $50 \%$ in the next 10 years. ${ }^{1,2}$ Diabetes mellitus (DM) is recognized as a huge burden for any health care system. It affects people of productive age and in recent years has also begun to affect young people. ${ }^{3}$

In Serbia about 600.000 people $(8.2 \%$ of the population) have been diagnosed with diabetes. According to the estimations of domestic experts and on the basis of the results of international studies, at least a half of those with type 2 diabetes have not been diagnosed and are not aware of their disease. ${ }^{4}$ Serbian national health surveys of the general population in 2006 and international data from 2012 have shown an increasing trend in the prevalence of diabetes, with reported rates of $5 \%$, and $12.35 \%$, respectively. ${ }^{5,6}$ The key risk factors identified were: BMI $25 \mathrm{~kg} / \mathrm{m}^{2}$, sedentary lifestyle, hypertension in young population and productive age population in Serbia. ${ }^{5}$

The majority of risk factors can be easily recognized or measured by health care providers and/or patients. Although adults may be aware that they possess such
Submission Date : 29-06-2015 Revision Date : 07-09-2015 Accepted Date :14-11-2015 DOI: 10.5530/ijper.50.1.12 Correspondence Address Prof Ljiljana Tasic Department of Social Pharmacy and Pharmaceutical Legislation, Faculty of Pharmacy, University of Belgrade, V. Stepe str. 450, 11221 Belgrade, Serbia. Tel:+381113951285 E-mail: ljtasic@pharmacy. bg.ac.rs

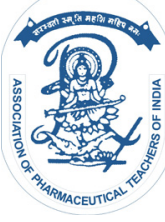

www.ijper.org 
characteristics, they may not know that clusters of these factors further amplify the risk of diabetes. Several prevention studies have shown that treatment of pre-diabetes with lifestyle changes can decrease the risk of progression to diabetes considerably. ${ }^{7-9}$

The Diabetes Prevention Project, which had been conducted in the USA demonstrated that for patients at high risk for diabetes, lifestyle changes such as loss of $7 \%$ of weight and 150 minutes of walking per week, decrease the risk of diabetes by $58 \%$.

There is a growing body of evidence that shows that intervention programs run by health care professionals, in ambulatory settings, and with community pharmacists' involvement, were effective at both preventing and managing cardiovascular disease (CVD) and diabetes. Despite the increasing number of studies showing that pharmacist intervention programs provide a clinical benefit and sensitivity in terms of patients outcomes, there are few studies that have examined the concept of multidisciplinary health care and collaborative practice in the context of community care settings and with pharmacist intervention. ${ }^{10-12}$

Diabetes management programs have been implemented in pharmacy practice using a range of different intervention such as educational interventions, counseling, ${ }^{13}$ risk screening, ${ }^{14,15}$ medication reviews, ${ }^{16}$ and usually accredited by national professional institutions. The American Association of Diabetes Educators (AADE) published the scope and standards for professional performance for diabetes educators specifically to address the provision of this care by pharmacists in their practices. ${ }^{17}$

Almost every country worldwide has strategies for the prevention of diabetes. In Serbia, a series of guidelines have been adopted, at the national level that is aimed at achieving more efficient diabetes care. These are the National Guidelines for diagnosis and treatment of Diabetes; ${ }^{18}$ National Guidelines for Prevention of Type 2 Diabetes $^{19}$ and the National Program for the Prevention of Diabetes and Early Detection of type 2 diabetes. ${ }^{20}$ For the first time, pharmacists' role in prevention of type 2 diabetes was recognized and defined by National Guidelines for Prevention of Type 2 Diabetes. This provides a great opportunity for pharmacists to play an active role in the prevention and management of Type 2 Diabetes and more generally for the development of pharmacy practice in Serbia. It has been argued that pharmacists are ideally suited to provide preventive care and chronic disease interventions for a number of reasons. For example, community pharmacists are highly accessible health professionals in both rural and urban communities and are often available without an appointment and beyond the hours of operation of many primary care medical clinics. In addition, patients see their pharmacist more frequently than their physician. As medicine therapy experts, pharmacists are capable of providing pharmaco therapeutic and educational interventions and are well positioned to play a greater role in primary health care. ${ }^{21}$

Clinical pharmacy services commonly include a number of different pharmacist interventions and are thus considered to be complex health interventions. ${ }^{22}$ In order to fully understand the complexity of pharmacist interventions practice-based research needs well design studies and tools to evaluate and describe the impact of clinical pharmacy services on patient outcomes. Furthermore, for policy makers an understanding of all components of the pharmacist interventions, and a process road map describing the setting and resources are important to ensure the quality of the research being used. ${ }^{23,24}$

Pharmaceutical care, as a professional orientation with a patient centered approach is not commonly implemented in community pharmacy practice in Serbia. A few local (municipality based) projects have been performed, and some international projects are ongoing, with specific issue and aims, but identification of risk factors of diabetes 2 in the pharmacy setting and postscreening pharmacist intervention was the first study in Serbia.

Following this rationale, our objectives were: to determine the risk factors for type 2 diabetes in adults visiting a community pharmacy; to determine the number, the types and describe the components of pharmacists' interventions in this context focusing on the feasibility of complex interventions in the community setting.

\section{MATERIAL AND METHODS \\ Study design and setting}

This pilot study was approved by the Pharmaceutical Chamber of Serbia as a part of the project titled: The research of model and quality of pharmaceutical care service in community pharmacy (approved $12^{\text {th }}$ December 2009). This study was designed by a working group which consisted of six members (three members from academia and three members from community pharmacies). A design was created after reviewing the scientific literature and according to professional practice. The study had a cross-sectional, multicenter design and was conducted from January 2010 to June 2011. It was conducted in 20 community pharmacies from all regions of Serbia (four from the northern region Vojvodina, 
eight from central Serbia, four from Belgrade, two from the western region, one from the eastern region, and one from the southern region). The pharmacies were public and private pharmacies, independent or a part of a pharmacy chain. The manager/owners of these pharmacies accepted our offer to participate in the study after written invitations were sent by the principal investigator (VKP). The study had two phases: preparation of tools and training of pharmacists (from January to May 2010) and project implementation in practice (from June 2010 to June 2011). The overall design and the tools used in the study were approved by Ethical Committee of the University of Belgrade, Faculty of Pharmacy.

\section{Tools used in this study}

We have used the questionnaire for type 2 diabetes risk estimation published by National Program for the Prevention of Diabetes and Early Detection of type 2 Diabetes (Appendix 1). This questionnaire consisted of eight themes which examined: the demographic characteristics of adults (age, gender ( 2 items)), and 1 question was asked for each of the following: body mass index (BMI), waist circumference, physical activity, eating of vegetables/fruits, intake of antihypertensive medications, and previous elevated level of blood glucose and diabetes family history.

\section{Educational Material (Leaflet)}

Based on the existing literature, Educational material (a leaflet) was developed by the principal investigator (VKP; available from authors on request) to facilitate the education of patients at risk of diabetes, and to support pharmacy based counseling sessions. This leaflet contains illustrated, motivational, information for participants regarding healthy lifestyle, healthy diet and how to selfmanage their health.

\section{Intervention Checklist}

To evaluate the process of screening participants for type 2 diabetes, a checklist was design by the principal investigator (VKP). Face validation was done by two pharmacists (one from pharmacy practice and one from academia). The checklist was then pilot tested in two pharmacy settings (during one week with 20 participants) to assess its acceptability in a real setting (Appendix 2). The Intervention checklist that was developed is consistent with the nine types of pharmacist's interventions for patients at risk of diabetes. It included counseling of patients about proper nutrition; counseling patients about the importance of physical activity and a healthy lifestyle; counseling patients about the importance of an annual preventive health check by their GP; providing the health education material (leaflet) to the patient; referral of the patient to the general practitioner (GP) based on assessment of risk; counseling of patients about the importance of weight control; recommendations to patients regarding herbal or traditional medicines and dietary supplements use; inviting patients to come back to the same pharmacy after their general practitioner visit; have a telephone communication with the patients GP and sending patient to him. All interventions should be marked on the check list (Appendix 2).

\section{Pharmacist training}

Pharmacists who were involved in the study and who recruited participants had to complete a one-day competency-based training and workshop. The training was accredited by the National Committee for accreditation for Continual Medical Education. The training was attended by 30 pharmacists who filled in pre and post training tests of their knowledge in relation to diabetes and the study tools.

The competency-based training focused on developing the pharmacists' knowledge and skills in relation to diabetes and the need to communicate and appropriately counsel the target patient population. The set of documents which were to be used in this study were also presented to the pharmacists during this training with full detail explanation and instructions. These documents included: A patient written consent-form, Questionnaire for type 2 diabetes risk estimation (Appendix 1), an intervention checklist (Appendix 2) and Educational material (leaflet) for participants.

\section{Participants recruitment, data collection and pharmacist interventions}

The Pharmacists randomly recruited the participants, who were willing to participate in the study, over a one year period. All of the participants were informed about the study aims and were asked to sign an informed consent before participation. The inclusion criteria for the study were: healthy or with a chronic disease, aged over 18 years. The exclusion criteria were being less than 18 years of age, and adults who were cognitively impaired and therefore could not complete the questionnaire. The recruitment process and communication with participants were performed in separate counseling areas of each community pharmacy. Every participant was asked to complete the risk assessment questionnaire for type 2 diabetes personally. Pharmacists were available to assist to participants with any questions about the questionnaire, to measure waist circumference, and calculate BMI. The risk level was calculated and data recorded 
in the questionnaire. The pharmacist then counseled the participant in accordance with the National program for prevention of diabetes and early diagnoses using the appropriate interventions from the set of nine different interventions tailored to the patients estimated risk level. Every intervention was then recorded for each patient using the Intervention checklist.

\section{Characterizing the Components of Pharmacists Interventions}

For the purpose of understanding the depth of pharmacist interventions a qualitative analysis was performed, ${ }^{25}$ using the DEPICT (a Descriptive Elements of Pharmacist Intervention Characterization Tool). ${ }^{23}$ This tool was developed to be used as reference guide to compare/ assess the main domains of the pharmacists interventions. The DEPICT was used here to assess the two tools used in our study (Appendix 1 and Appendix 2). ${ }^{23}$

\section{Data analysis}

The cohort was stratified on four age group: 18-45, 45-54; 55-64; 64. Demographic characteristics and clinical data were analyzed using the descriptive statistics. Quantitative analysis of number of interventions was undertaken using the chi-square test. The numerical data were analyzed using the statistical program SPSS version 18.0. The description of components of pharmacist intervention as process of delivery of pharmaceutical care service, that is the qualitative component of our study, was independently analyzed by an experienced researcher $(\mathrm{Lj} \mathrm{T})$.

\section{RESULTS}

\section{Evaluation of the participants' risk level for type 2 diabetes}

Pharmacists from 20 pharmacies recruited 403 participants. A further 69 eligible people refused to participate in the study (response rate $82.88 \%$ ). Demographic and clinical characteristics of the participants are presented in Table 1.

Most of the participants were women, younger than 45 years and had healthy lifestyle habits. Two hundred and thirty two participants $(69.5 \%)$ were involved in daily physical activity lasting for at least 30 minutes. In all 285 $(85 \%)$ participants ate some fruit and vegetables every day. A large proportion of the sample reported risk factors for cardiovascular disease. Antihypertensive medications have been taken by $54.7 \%$ of participants (Table 1). About one-third of the participants ( $\mathrm{n}=117$, $35 \%$ ) have ever registered a high blood glucose level during routine health checks, during illness or preg- nancy. Also, less than a half of the participants had a positive family history of diabetes (46\%) (Table1).

Over $69 \%$ of participants were either overweight (BMI range from 25-30) or obese (more than 30) (obesity). Approximately $77 \%$ of participants had waist circumference measurements above the recommended values $(<80$ for female and $<94$ for male gender) (National guidelines for obesity, 2004).

The participants were divided into four age groups, according to Questionnaire for type 2 diabetes risk estimation, and risk for developing diabetes in the next 10 years was estimated and results are presented in Table 2. Based on the estimated risk degree, the prevalence rate of diabetes in our cohort is $2.69 \%$. Approximately $10.8 \%$ of participants aged between $45-54$ and $9.6 \%$ of those aged 55-64 recorded high and very high risk scores. In the latter group (55-65 age groups) the moderate diabetes 2 risk score was present in 32 adults $(9.6 \%)$. Interestingly, into the population group aged below 45 years $(37.72 \%$ of our cohort) 59 adults $(17.8 \%)$ had low and 31 adult $(9.3 \%)$ had moderate diabetes 2 risk scores.

\section{Determination of the number and type of pharmacists' interventions}

Pharmacist interventions were targeted according to risk degree estimated and was based on the interventions listed in the checklist. (Appendix 2). Quantitative results include the absolute measures (number of participants and number of the interventions sorted by five categories of risk) and relative measures (number of pharmacists' interventions per participants $\mathrm{PI} / \mathrm{pP}$ ). These results are presented in Table 3.

The pharmacists made a total of 1328 intervention during the study. The results indicated that the number of pharmacists' interventions depended on participants' risk score (365 for moderate and 461 for high risk level patients). Using the relative measurement unit (PI/pP) we were able to assess the quality of pharmacist care related to clinical markers e.g. risk factors. For low and slight risk level participants a rate of 2.27 and 3.85 interventions per person were estimated. The average value of $\mathrm{PI} / \mathrm{pP}$ was 4.02 , and in patients with moderate, high and very high risk the estimated value was $5.28,5.42$ and $3.55 \mathrm{PI} / \mathrm{pP}$, respectively. Incidentally, a small number of interventions were done to the participants with very high risk factor scores for diabetes 2 (32 interventions for 9 participants), however, the appropriate types of intervention have been done with this group. There is a statistically significant difference between number of pharmacists interventions and number of participants 
related to risk level groups (Chi $\mathrm{sq}=31.25, \mathrm{p}<0.001)$. Among the nine types of pharmacists' interventions for early screening of type 2 diabetes, an important intervention involved 'referring patients to a general practitioner (GP). In total 97 participants were referred to a GP, of these 52 with a high risk score and 38 with a moderate risk score. The educational materials (leaflet) were handed out to 206 participants $(61.7 \%$ of study population, e.g. $15.34 \%$ of total interventions) (Table 3).

\section{Description of components of pharmacist interventions}

The classification of the nine interventions for prevention of type 2 diabetes was designed based on pharmacy practice in real word settings in Serbia within context of operational management and environment and resources. It was developed for the purpose of evaluation of the processes associated with of the delivery of complex clinical pharmacy services. A qualitative description of the components (domains) of the "pre-process" that is, the estimation of risk scores (screening) and the "process itself " that is pharmacist interventions (counseling) was performed. Two tools (Questionnaire and Intervention checklist) used in this study were described using the DEPICT Tool. ${ }^{23}$ The results are presented in Table 4.

The DEPICT tool consist of 12 domains (from A to M). Domains $\mathrm{A}$ to $\mathrm{D}$ form a general descriptor, two of these domains A. contact with patients and D. target population, can be seen in the $1^{\text {st }}$ (demographic) and in the $2^{\text {nd }}$ (clinical data $\mathrm{q} 2-\mathrm{q} 8$ and) parts of the Questionnaire. The other two general domains, that is, B. timing and C. setting are present in both our tools (Questionnaire and Intervention checklist).

Operational descriptors of components of the clinical pharmacy service (domains $\mathrm{E}$ to $\mathrm{M}$ ) match with the 'construct' of tools used for the evaluation of complex pharmacist interventions (screening and counseling). Domain E. clinical data sources, corresponded with the clinical part of Questionnaire (that is $\mathrm{q} 2-\mathrm{q} 8$ ); Domain F., assessment comprises the pharmacist's calculation of patients risk degree and profile. Knowing the patient's profile allowed the pharmacist to offer a tailored set of interventions, of good quality, which should be evaluated in follow-up patients visit (e.g. life style changes) or by patients' satisfaction measurement. Domain G. pharmacist's autonomy clearly meshes with a personal decision about the number and type of interventions delivered to each patient; $\mathrm{H}$. pharmacist communication, this can be seen in activities associated with recommendations for supplement use and communication with GPs. Domain I. support resources, this comprised the education material that is the leaflet. J. education and counseling domain comprised four types of counseling activity/interventions; domain L. follow-up, involves the invitation of patients to come back to the same pharmacy; domain M. other actions (usually supportive activity) was of two types of interventions e.g. recommendation of some product and referral patients to GPs.

\section{DISCUSSION}

In the last few years different pharmaceutical care services have been offered through community pharmacies in Serbia either as local pharmacy projects, or as a part of pilot projects in public health campaigns (counseling patients about diabetes prevention, counseling of healthy life styles to prevent obesity, counseling asthma patients). ${ }^{26-28}$

Our study is the first study, a pilot study, in Serbia focusing on type 2 diabetes screening. As well this is the first study with the specific intention of describing the components, and processes associated with complex pharmacy care services provided in community pharmacy settings for those at risk of type 2 diabetes. Our study provided an opportunity to conduct a screening program for type 2 diabetes in pharmacy settings using a risk assessment questionnaire. Participants were targeted from the labor active population, and so an early recognition of the extent of risk was important for prevention of diabetes especially in this population.

Involvement of pharmacists in screening for type 2 diabetes can increase the early detection of the at risk population and has the potential to slow progression to micro vascular and macro vascular complications. ${ }^{29}$ Several studies from one Australian scientific group have addressed the issue of patients' satisfaction with pharmacists' service in diabetes disease management, satisfaction with self-management, and satisfaction with knowledge ${ }^{14,30}$ have shown the effectiveness of a community pharmacy delivered diabetes care service, using a step screening model. In our study we recognized and used a model of complex intervention (screening and counseling).

According to data obtained from the Institute of Public Health of Serbia for 2012 the incidence rate of type 2 diabetes per 100.000 inhabitants were 208.9, 329.7, $473.5,559.5,638.7$ in 2012 , in population age groups $45-49,50-54,55-59,60-64,65-69$, respectively ${ }^{4}$. In the $6^{\text {th }}$ Diabetes Atlas a prevalence rate of type 2 diabetes in Serbian population was 2.89 which were near the prevalence rate estimated in our study (2.69). That reassured us that the patient sampling was accurate and the design 
Table 1: Demographic characteristics of participants and risk factor estimation a Demographic characteristics of participants $(n=334)$ Gender

Male

Female Age $<45$ $45-54$ $55-64$ $>65$

Risk factors: participants answering "yes" to a risk factor on the assessment tool BMI (kg/m2)b $<25$ 25-30 $>30$

\begin{tabular}{l|l}
$\mathrm{n}$ & $\%$
\end{tabular}

\begin{tabular}{l|l} 
& \\
91 & 27.2
\end{tabular}

\begin{tabular}{l|l}
\hline 43 & 72.8
\end{tabular}

26

\begin{tabular}{l|l}
98 & 29.3
\end{tabular}

\begin{tabular}{l|l}
97 & 29.0
\end{tabular}

\begin{tabular}{l|l}
13 & 3.8
\end{tabular}

\begin{tabular}{|c|c|c|}
\hline $\begin{array}{l}\text { Risk factors: participants answering "yes" to a risk factor on the } \\
\text { assessment tool }\end{array}$ & & \\
\hline \multicolumn{3}{|l|}{ BMI $(\mathrm{kg} / \mathrm{m} 2) \mathrm{b}$} \\
\hline$<25$ & 103 & 31.8 \\
\hline $25-30$ & 133 & 39.8 \\
\hline$>30$ & 98 & 29.3 \\
\hline \multicolumn{3}{|l|}{ Waist circumference $(\mathrm{cm}) \mathrm{c}$} \\
\hline$<94(\mathrm{M}) \quad<80(\mathrm{~F})$ & 75 & 22.4 \\
\hline $94-102(\mathrm{M}) \quad 80-88(\mathrm{~F})$ & 93 & 27.8 \\
\hline$>102(\mathrm{M}) \quad>88(\mathrm{~F})$ & 166 & 49.8 \\
\hline Have physical activity during the day 30 minutes & 232 & 69.5 \\
\hline Every day eat vegetables and fruit & 285 & 85.0 \\
\hline Ever taking antihypertensive medication & 183 & 54.7 \\
\hline $\begin{array}{l}\text { Ever measured high blood glucose level in routine examination, during } \\
\text { illness or pregnancy }\end{array}$ & 117 & 35.0 \\
\hline Positive family history & 154 & 46.0 \\
\hline
\end{tabular}

${ }^{a}$ Questionnaire for type 2 diabetes risk estimation (see Appendix 1 )

${ }^{b}$ participant fill the weight $(\mathrm{kg})$ and height $(\mathrm{m})$ in the questionnaire form and pharmacist calculating BMI-Body mass index cpharmacist measured the circumference $(\mathrm{cm})$

\section{Table 2: Evaluation of the risk degree * according to age groups}

\begin{tabular}{|c|c|c|c|c|}
\hline & \multicolumn{4}{|c|}{ Age groups $\mathbf{n}(\%)$} \\
\hline Degree of risk & $<\mathbf{4 5}$ & $\mathbf{4 5 - 5 4}$ & $\mathbf{5 5 - 6 4}$ & $>\mathbf{6 5}$ \\
\hline Low & $59(17,8)$ & $10(3,0)$ & $4(1,2)$ & \\
\hline Slight & $31(9,3)$ & $35(10,5)$ & $28(8,4)$ & $4(1,2)$ \\
\hline Moderate & $18(5,4)$ & $17(5,1)$ & $32(9,6)$ & $2(0,6)$ \\
\hline High & $16(4,8)$ & $34(10,2)$ & $29(8,7)$ & $5(1,5)$ \\
\hline Very high & $2(0,6)$ & $2(0,6)$ & $3(0,9)$ & $2(0,6)$ \\
\hline
\end{tabular}

* Risk degree was calculated using the Questionnaire for type 2 diabetes risk estimation (Appendix 1). According to the questionnaire risks degree were divided into five categories (proportion of people who will develop DM within 10 years): Low $\leq 7$ points, one of 100 people; Slight 7-11 points, one of 25 people; Moderate 12-14 points, one of 6 people; High 15-20 points, one of 3 people; Very high $\geq 20$ points, one of 2 people.

of our pilot study had been properly done. The most significant population for the prevention of diabetes is the 45 to 54 age group (29.34\% of our study). This compares with the recent Hungarian diabetes prevention study with an average age $52.83^{32}$ and in a Nova Scotia pre-diabetes study the average age of the study population was approximately 57 year. ${ }^{33}$

The prevalence rate detected in our study was lower than similar published studies. Namely, the results from a pilot screening program in England show an overall prevalence of $4.08 \%$ including $0.54 \%$ undiagnosed. ${ }^{34}$ One possible explanation for these differences between country could be related to a healthier lifestyle estimated in our study group, which is also supported by national epidemiologically data from public health survey. ${ }^{5}$ Population level approaches and targeted (opportunistic) screening approaches have been used in many studies. We used an opportunistic screening approach to health prevention in our study. The screening of patients was evaluated and risk level estimated by pharmacists and 
Table 3: Number of participants (patients), interventions and types of pharmacists' interventions related to risk degree* group

\begin{tabular}{|c|c|c|c|c|c|c|}
\hline Risk degree* & low & slight & moderate & high & very high & Total \\
\hline Number of participants (\%) & $73(21.86)$ & $98(29.34)$ & $69(20.66)$ & $85(25.45)$ & $9(2.69)$ & $334(100.00)$ \\
\hline $\begin{array}{l}\text { Number of pharmacists' } \\
\text { interventions, } \mathrm{n}(\%)\end{array}$ & $166(12.36)$ & $319(23.75)$ & $365(27.18)$ & $461(34.33)$ & $32(2.38)$ & $1343(100.00)$ \\
\hline $\begin{array}{c}\text { Number of pharmacists' } \\
\text { interventions/ Number of } \\
\text { participants (PI/pP) }\end{array}$ & 2.27 & 3.25 & 5.29 & 5.42 & 3.55 & $\begin{array}{c}4.02 \\
\text { (average) }\end{array}$ \\
\hline $\begin{array}{c}\text { Type of intervention, } \\
\mathrm{n} \text { intervention (\% of total } \\
\text { intervention this type ) }\end{array}$ & & & & & & $\begin{array}{l}\text { Total interventions by type } \\
\text { n (\% of all interventions) }\end{array}$ \\
\hline $\begin{array}{l}\text { 1. Counseling of patients about } \\
\text { proper nutrition }\end{array}$ & $60(20.3)$ & $83(28.1)$ & $66(22.4)$ & $80(27.1)$ & $6(2.0)$ & 295 (21.965) \\
\hline $\begin{array}{c}\text { 2. Counseling patients about } \\
\text { the importance of continued } \\
\text { physical activity and healthy } \\
\text { lifestyle }\end{array}$ & $61(20.7)$ & $84(28.5)$ & $64(21.7)$ & $80(27.1)$ & $6(2.0)$ & 295 (21.965) \\
\hline $\begin{array}{c}\text { 3. Counseling patients about } \\
\text { the annually preventive health } \\
\text { check by their GP }\end{array}$ & $4(3.8)$ & $80(75.5)$ & $11(10.4)$ & $11(10.4)$ & $0(0.0)$ & $106(7.89)$ \\
\hline $\begin{array}{c}\text { 4. Providing the health } \\
\text { education material (leaflet) to } \\
\text { the patients }\end{array}$ & 39 (18.9) & $58(28.2)$ & $45(21.8)$ & $61(29.6)$ & $3(1.5)$ & $206(15.34)$ \\
\hline 5. Referral of patients to the GP & $0(0.0)$ & $2(2.1)$ & $38(39.2)$ & $52(53.6)$ & $5(5.2)$ & $97(7.22)$ \\
\hline $\begin{array}{c}\text { 6. Counseling patients about } \\
\text { the importance of weight } \\
\text { control }\end{array}$ & $2(1.3)$ & $6(3.9)$ & $61(39.9)$ & $78(51.0)$ & $6(3.9)$ & $153(11.39)$ \\
\hline $\begin{array}{c}\text { 7. Recommendation to } \\
\text { patients for herbal or traditional } \\
\text { medicines and dietary } \\
\text { supplements use }\end{array}$ & $0(0.0)$ & $5(11.4)$ & $30(68.2)$ & $9(20.5)$ & $0(0.0)$ & $44(3.28)$ \\
\hline $\begin{array}{l}\text { 8. Invite patients to come back } \\
\text { to the same pharmacy after } \\
\text { GP visits }\end{array}$ & $0(0.0)$ & $1(0.8)$ & $50(37.9)$ & $75(56.8)$ & $6(4.5)$ & $132(9.83)$ \\
\hline $\begin{array}{l}\text { 9. Have a telephone } \\
\text { communication with the } \\
\text { patient's GP and sending } \\
\text { patient to him }\end{array}$ & $0(0.0)$ & $0(0.0)$ & $0(0.0)$ & $15(100.0)$ & $0(0.0)$ & $15(1.12)$ \\
\hline Total, $\mathrm{n}(\%)$ & $166(12.36)$ & $319(23.75)$ & $365(27.18)$ & $461(34.33)$ & $32(2.38)$ & $1343(100.00)$ \\
\hline
\end{tabular}

* Risk of developing type 2 diabetes in the next 10 years: Low $\leq 7$ points, one of 100 people; Slight 7-11 points, one of 25 people; Moderate 12 - 14 points, one of 6 people; High 15-20 points, one of 3 people; Very high $\geq 20$ points, one of 2 people. GP-general practitioner.

pharmacists' interventions were adequately performed according to a risk score.

A high risk of diabetes was detected in the age groups 45-54 and 55-64. Two participants from the 45-54 age grouping and three from the 55-64 year age group were at a very high risk of diabetes (see Table 2). This is a working population that could be healthy and more socio-economically productive. Therefore, this is an important sign for the need to implement broader, community based preventive health services in Serbia which should allow a timely diagnosis and help prevent the type 2 diabetes. Community based pharmacists are ideally located to provide this type of service. In a health technology assessment of pharmacists' impact on clinical outcomes, it was concluded that screening for late complications associated with diabetes could reduce the occurrence of retinopathy by $50 \%$ as well as reduce foot-related problems. ${ }^{29}$

Pharmacists, at the primary health-care level, have an important role in the prevention and treatment of chronic, non-communicable diseases because of their direct contact with patients. The role of pharmacists has been recognized in the National Guidelines for Type 2 Diabetes Prevention, but not implemented in practice enough. There is a need to encourage pharmacists in order to involve them in all national and local screening programs, as well to create national projects and programs. From the perspective of management of metabolic syndrome, population level approaches, and those targeted at people at high-risk, need to be balanced. A small reduction in risk in a large number of people may prevent many more cases, than treating a 


\begin{tabular}{|c|c|c|}
\hline 12 domains in DEPICT & $\begin{array}{l}\text { Screening ('pre-process') } \\
\text { Tool-Questionnaire }\end{array}$ & $\begin{array}{l}\text { Counseling ('process itself') } \\
\text { Tool-Intervention Checklist }\end{array}$ \\
\hline A. Contact with the patient & $\begin{array}{c}\text { demographic } \\
1^{\text {st }} \text { part of Questionnaire }\end{array}$ & \\
\hline B. Timing of the intervention & at the regular visit (drug dispensing) & $\begin{array}{c}\text { after screening } \\
\text { time spend on counseling * }\end{array}$ \\
\hline C. Setting of the intervention & community pharmacy & community pharmacy \\
\hline D. Target population & $\begin{array}{c}\text { Estimated risk score } \\
2^{\text {nd }} \text { part of Questionnaire }\end{array}$ & \\
\hline E. Clinical data sources & $2^{\text {nd }}$ part of Questionnaire & \\
\hline F. Assessment & pharmacist calculation of patients risk degree & $\begin{array}{l}\text {-assessment of patients profile; } \\
\text {-life style changes }{ }^{\star *} \\
\text {-patients satisfaction }\end{array}$ \\
\hline G. Pharmacist's autonomy & & $\begin{array}{l}\text { personal decision of number and type of } \\
\text { intervention for every patients. }\end{array}$ \\
\hline H. Pharmacist communication & & $\begin{array}{l}\text {-communication with patients; } \\
\text {-communication with GP. }\end{array}$ \\
\hline $\begin{array}{l}\text { I. Support resources provided } \\
\text { by the pharmacist }\end{array}$ & & distribution of health education material-leaflet. \\
\hline J. Education and counseling & & $\begin{array}{c}\text { four types of intervention at counseling session: } \\
\text {-about proper nutrition } \\
\text {-about the importance of continued physical } \\
\text { activity and healthy lifestyle } \\
\text {-about the annually preventive health check by } \\
\text { their GP } \\
\text {-about the importance of weight control }\end{array}$ \\
\hline L. Follow-up & & $\begin{array}{l}\text { invitation of patients to come back to the same } \\
\text { pharmacy. }\end{array}$ \\
\hline M. Other actions & & $\begin{array}{c}\text {-recommendation of some product; } \\
\text {-referral patients to GP. }\end{array}$ \\
\hline
\end{tabular}

*time spend on counseling - the data collected from a small number of patients ( $\leq 10 \%)$ and not included in study.

**life style changes - assessment of behavior' s changes possible through the follow up visit that had not being design in our study; assessment of patient profile included planning of set of intervention for counseling session considering lifestyle advices.

*** patients satisfaction - the data collected but not included in this study.

small number at higher risk. ${ }^{35}$ Pharmacists can provide a set of numerous interventions tailored to the individual patients profile and level of risk.

In our study pharmacists informed patients about proper nutrition, as well as the importance of continued physical activity and healthy lifestyle. Lifestyle advice from pharmacists can have a positive effect on the risk factors for diabetes and other non-communicable disease. ${ }^{36}$ The positive influence of educational sessions and written material (leaflet) on prevention, health promotion and motivation of the patients to improve their health has also been shown. ${ }^{15}$ The support of patients being managed with diabetes involves different types of intervention such as a medication adherence, identification of medication problems or lifestyle advice (e.g. exercises, diet, and foot care). Our results of the number and types of intervention are in agreement with existing literature, however, there was a the relatively low proportion $(61,7 \%)$ of patients provided with the education leaflet. A possible explanation for this result is lack of time, or awareness of the usefulness of supportive tools.

In Hungary, a National Committee on pharmaceutical care completed a one year project implementing a diabetes prevention program in pharmacies. A total of 22.398 citizens from all over Hungary evaluated by pharmacist intervention. The conclusion was that pharmacists had an active role to play in diabetes prevention and pharmacists were well placed to identify individuals at high risk. ${ }^{32}$ During project period, the pharmacists sent nearly $20 \%$ of the patients to physicians, thus facilitating an early recognition of diabetes in several patients. In our study $29.04 \%$ patients were referred to the GP by pharmacist intervention. This is because we used a targeted screening approach, contrary to the population approach used in the previously mention study. A marked improvement in self-monitoring of blood glucose in type 2 diabetes patients in the German population resulted from 
Appendix 1

QUESTIONNAIRE FOR TYPE 2 DIABETES RISK ESTIMATION

Pharmacy

No.

Date

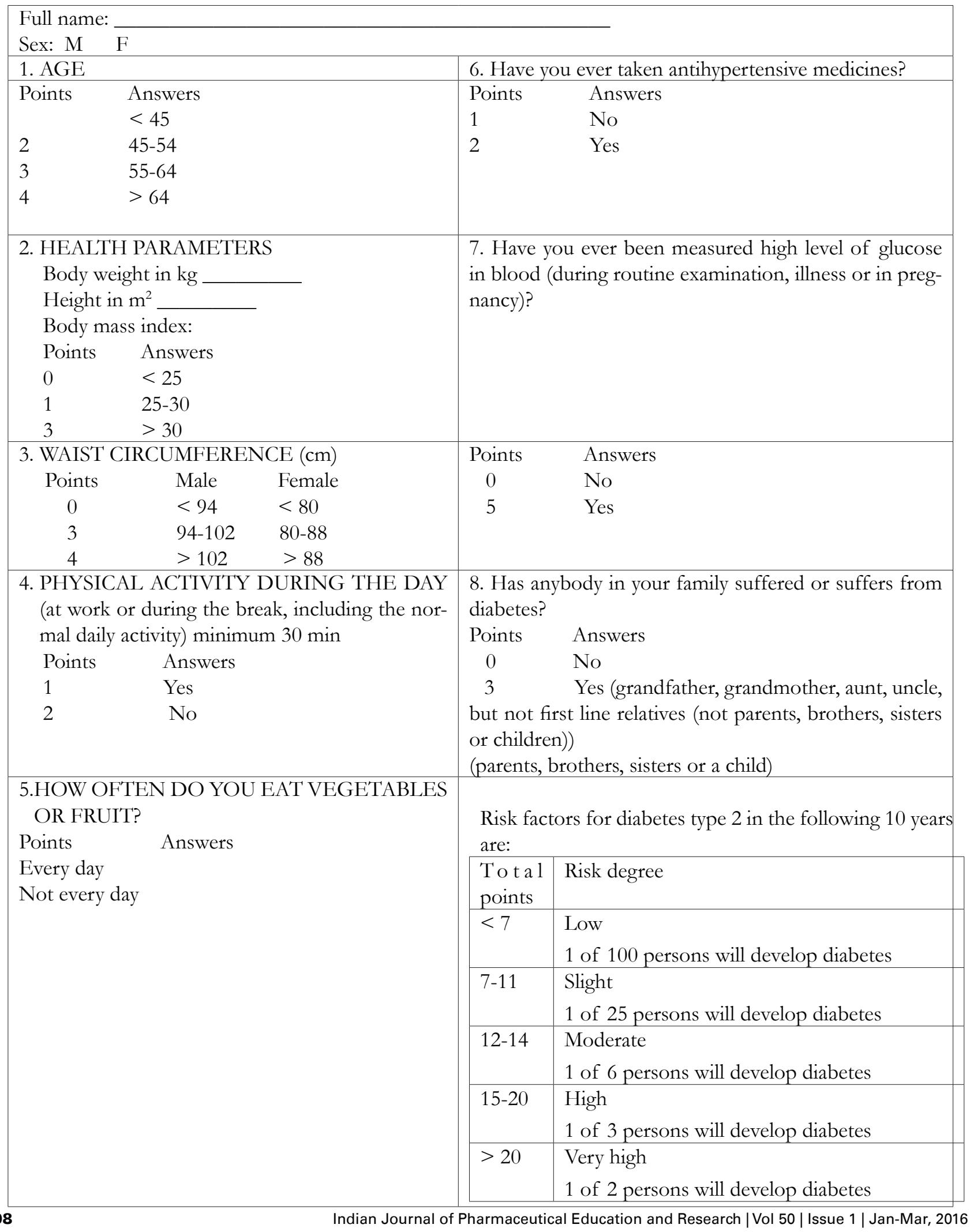




\section{INTERVENTION CHEKLIST}

Please circle the intervention that you offered to patients according to their diabetes 2 risk degree (number of points estimated by Questionnaire for type 2 diabetes risk estimation)

\begin{tabular}{|c|l|}
\hline P & \multicolumn{1}{|c|}{ PHARMACISTS INTERVENTIONS } \\
\hline 1. & Counseling of patients about proper nutrition \\
\hline 2. & Counseling patients about the importance of continued physical activity and healthy lifestyle \\
\hline 3. & Counseling patients about the annually preventive health check by their general practitioner (GP) \\
\hline 4. & Providing the health education material (leaflet) to the patients \\
\hline 5. & Referral of patients to the general practitioner* (GP) \\
\hline 6. & Counseling patients about the importance of weight control \\
\hline 7. & Recommendation to patients for herbal or traditional medicines and dietary supplements use \\
\hline 8. & Invite patients to come back to the same pharmacy after general practitioner (GP) visits \\
\hline 9. & $\begin{array}{l}\text { Have a telephone communication with the patient's general practitioner (GP) and sending patients to } \\
\text { him* }\end{array}$ \\
\hline
\end{tabular}

*patients with high or very high risk degree

Name (signature) of pharmacist:

Time (min) spend on estimation of risk score and counseling

pharmacists' interventions is reported in a study done by Muller et al. ${ }^{37}$ In this study it was shown that community pharmacies specializing in diabetes care were able to provide service in self-monitoring of blood glucose with better outcomes for patients. The study found that patients accepted pharmacists' intervention in the pharmacy and also wanted to take a more active role in managing their health care. ${ }^{37}$ The former study has been design as an intervention study with follow up over time from base line. This is quite a different approach to our opportunistic screening approach in diabetes prevention with post-screening cognitive service intervention (that is with complex intervention). In systematic reviews of diabetes quality improvement interventions ${ }^{38}$ there is consistent evidence to indicate that a number of interventions, for example, patient education and support, telemedicine, and provider role changes, appeared to improve diabetes quality of care. Also, there was some evidence that tailoring interventions to specific cultural or age groups might be of benefit to the effectiveness of the treatment strategy. ${ }^{38}$ Considering this, pharmacists in our study provided appropriate, individually targeted interventions, provided good knowledge and clinical skills.

Our qualitative analysis was designed to provide a better understanding of complexity of pharmacy services as a whole, and particularly counseling service for patients with estimated diabetes risk. The DEPICT tool are useful in that it allowed us to describe components (domains), of some key elements of the process that we recorded and documented during the intervention, but in real word setting in our pilot study. This provides additional support and recommendations for researchers of pharmacy practice to use DEPICT tool as reference guide. To some extent the tool used in our study may be useful for the evaluation of quality in future studies of pharmacist counseling services. For the outcomes measurements (clinical, humanistic, or economic) and impact of pharmacist intervention a proper endpoint and follow-up study design should be obligatory. The previous suggestion to pharmacy practice researchers is primarily based on experience from our study, the professional and academic practice of authors and affected by systematic reviews of Charrois 
T. et al. ${ }^{31}$ Indeed, we followed the Weinberger et al. ${ }^{39}$ recommendation that the 'dose' of health service intervention should be quantified wherever possible, as well clearly defining the intervention and setting. Our findings provide a credible and feasible model for the future of pharmacy counseling services in the prevention of diabetes type 2 in Serbia. The risk assessment questionnaire for type 2 diabetes was suitable for pharmacists and for use in community pharmacy settings. The classification of the types of pharmacists' interventions used in our study could be useful for further development of pharmacy services in primary health care. Careful organization of public health services within the community pharmacy setting, as well as the clinical, social and economic outcome measurements have been the imperatives for achieving citizens' health. The literature relevant to screening for diabetes has indicated that mass screenings are not necessarily more cost-effective than the recommended opportunistic screenings, possibly performed together with screenings for other lifestyle diseases. ${ }^{29}$ This is an excellent chance for the pharmacists and community pharmacy to get involved and be proactive with other health care professionals to modulate preventive health services and centers.

A growing number of pharmacists' interventions that were offered to patients according to their risk score presented a great opportunity for pharmacists to prevent type 2 diabetes. Counseling patients could prevent new diabetes patients, or help in early diagnosis of diabetes type 2 , especially in patients from the labor population.

\section{LIMITATIONS}

This study had several limitations. The national Questionnaire for type 2 diabetes risk estimation collects the data from participants about BMI, age and waist circumference in categories rather than as precise estimations of these values. The study was conducted in a small number of pharmacies which were well geographically distributed. A small number of pharmacies were included from Belgrade which is the capital and has the most number of pharmacies that serve about $23 \%$ of the Serbian population and so may have been under-represented.

\section{CONCLUSION}

To summarize, Pharmacists have an important role in public health particularly to raise awareness, provide access to screening to identify those at risk, and make early intervention in chronic disease management possible $^{40}$ On the whole, the development and implementation of complex interventions to improve health raises issues about the nature and composition of such intervention. Hence, the results of our pilot study support pharmacists' efforts in developing the future model of service of "Prevention of Type 2 Diabetes in Pharmacies" in Serbia. The risk assessment questionnaire for type 2 diabetes was suitable for pharmacists and community pharmacy settings to detected risk levels in the adult population. The number and type of pharmacist interventions undertaken in counseling sessions were found to be adequate to participants clinical profile and practitioners balanced the population and opportunistic approaches. From the eight domains (operational descriptor of clinical pharmacy service in DEPICT) the main component are 'education and counseling' with four type (items) of intervention performed in post-screening counseling service of adult population. The tools used in our study are feasible for further development of the clinical services in community pharmacy, certainly with follow-up in study design. Finally, the careful design of complex interventions and modeling of the preventive services within the community pharmacy setting, with the clinical, social and economic outcome measurements are equally important processes and it should operate in parallel with pharmacy practice research, which is a relatively new field, with the potential to have a huge impact on the contemporary healthcare system.

\section{ACKNOWLEDGEMENTS}

The authors would like to thank the pharmacists who helped the enrolment of patients and patients who were willing to participate in the study. We would like to thank Professor Dr Alexandra Clavarino (School of Pharmacy, University of Queensland) for review and comment and English improvement. The study is part of research project no 41012 funded by Ministry of Education, Sciences and Technology Development of Serbia.

\section{ABBREVIATION USED}

T2D: type 2 diabetes; PI : pharmacists' interventions; CI : Complex intervention ; DEPICT : Descriptive Elements of Pharmacist Intervention Characterization Tool; CP: community pharmacy; DM: Diabetes mellitus; BMI: body 
mass index; CVD: Cardiovascular disease; GP: General practitioner; AADE: The American Association of Dia-

betes Educators.

\section{Summary}

- The determination the risk factors for T2D in adults visiting a community pharmacy in Serbia was performed as $\mathrm{PI}$ and the component of $\mathrm{Cl}$ was described.

- Prevalence rate of T2D estimated in our Pilot study was 2.69 and the most significant population group with high and very high T2D risk score was in age group 45-54 $(10.80 \%)$.

- The average value of $\mathrm{Pl} /$ per patients was 4.02 and the number and type of $\mathrm{Pl}$ in counseling session adequate to participants clinical profile.

- The main component of this $\mathrm{Cl}$ of pharmacist's (using DEPICT) are 'education and counseling' with four types (items) of PI performed in counseling session.

\section{Pictorial Abstract}
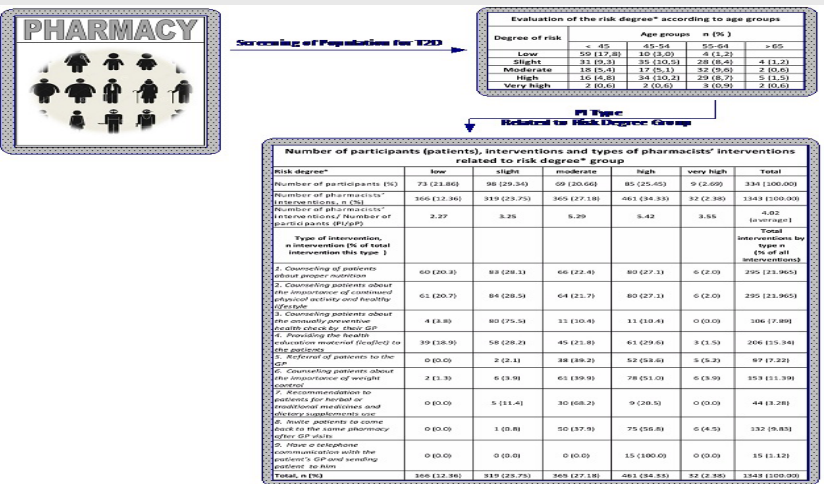

\section{About Authors}

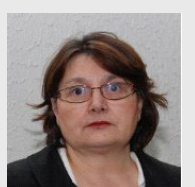

Ljiljana Tasic is an Full Professor and founder in the Department of Social Pharmacy and Pharmaceutical Legislation, Faculty of Pharmacy in Belgrade University; teaching students in the filed of pharmacy practice, health management, medicines policy, pharmacoepidemiology and quality in health care. From 2012. she is Director of Center for development of pharmacy practice. During 2014. she has position of Visiting Professor at University of Queensland (AU). She is also published about 170 publication, 13 chapters in monographs and books, 4 books. Her research interest in: pharmacists' education, public health, quality in medicines use (in elderly, in pregnancy).

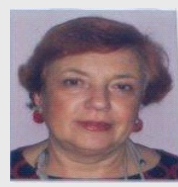

Vukic Kocic-Pesic graduated in Bacherol (1979) and in Master's of Pharmaceutical science (1991.) on Faculty of Pharmacy, University of Belgrade, as well completed MA 2007 at the same Univeristy. Her professional and scientific focus on the evaluation of pharmacy practice, performance management in pharmacy and quality in health care service. Working more than 25 years in pharmacy chain "Pharmacy Belgrade" she continued as QA manager on business development in company ADOC to implement the pharmaceutical care in pharmacy practice.

\section{REFERENCES}

1. Danaei G, Finucane MM, Lu Y, Singh GM, Cowan MJ, Paciorek CJ, et al. National, regional, and global trends in fasting plasma glucose and diabetes prevalence since 1980: systematic analysis of health examination surveys and epidemiological studies with 370 country-years and $2 \cdot 7$ million participants. Lancet. 2011; 378(9785): 31-40.

2. World Health Organization. Global Status Report on Non-communicable Diseases 2010. Description of the Global Burden of NCDs, Their Risk Factors and Determinants. World Health Organization; 2011.

3. National Health Service Choice. Diabetes, Type 2 - Treatment [online]. 2014 [cited 2014 Jan 15]. Available from: URL: http://www.nhs.uk/Conditions/ Diabetes-type2/Pages/Treatment.aspx

4. Institute of Public Health of Serbia, Dr Milan Jovanović-Batut". Incidence and mortality of diabetes in Serbia [online]. Belgrade, Serbia: Institute of Public Health of Serbia “Dr Milan Jovanović-Batut”; 2012 [cited 2014 Jan 29]. Available from: URL: http://www.batut.org.rs/download/publikacije/Registar\%20za\%20 dijabetes\%20u\%20Srbiji\%202012.pdf

5. Ministry of Health Republic of Serbia. National Health Survey Serbia, 2006 Key findings [online]. Serbia: Ministry of Health Republic of Serbia; 2007 [cited 2014 Feb 12]. Available from: URL: http://www.batut.org.rs/download/ publikacije/National\%20Health\%20Survey\%20Serbia\%202006.pdf

6. International Diabetes Federation. Diabetes Atlas-Sixth edition; 2013 [cited 2014 Feb 20]. Available from: URL: http://www.idf.org/atlasmap/atlasmap

7. Diabetes Prevention Program Research Group. Reduction in the incidence of type 2 diabetes with lifestyle intervention or metformin. N Engl J Med. 2002; 346(6): 393-403.

8. Pan X-R, Li G-w, Hu Y-H, Wang J-X, Yang W-Y, An Z-X, et al. Effects of diet and exercise in preventing NIDDM in people with impaired glucose tolerance: the Da Qing IGT and Diabetes Study. Diabetes Care 1997; 20(4): 537-44.

9. Tuomilehto J, Lindström J, Eriksson JG, Valle TT, Hämäläinen $H$, Ilanne-Parikka $\mathrm{P}$, et al. Prevention of Type 2 Diabetes Mellitus by Changes 
in Lifestyle among Subjects with Impaired Glucose Tolerance. N Engl J Med. 2001; 344(18): 1343-50.

10. Armor BL, Britton ML, Dennis VC, Letassy NA. A review of pharmacist contributions to diabetes care in the United States. J Pharm Pract. 2009; 23(3): 250-64.

11. Machado M, Bajcar J, Guzzo GC, Einarson TR. Sensitivity of patient outcomes to pharmacist interventions. Part I: systematic review and meta-analysis in diabetes management. Ann Pharmacother. 2007; 41(10): 1569-82.

12. Sisson E, Kuhn C. Pharmacist roles in the management of patients with type 2 diabetes. J Am Pharm Assoc. 2008; 49 Suppl 1: S41-5.

13. Ali M, Schifano F, Robinson P, Phillips G, Doherty L, Melnick P, et al. Impact of community pharmacy diabetes monitoring and education programme on diabetes management: a randomized controlled study. Diabet Med. 2012; 29(9): e326-e3.

14. Krass I, Mitchell B, Clarke P, Brillant M, Dienaar R, Hughes J, et al. Pharmacy diabetes care program: analysis of two screening methods for undiagnosed type 2 diabetes in Australian community pharmacy. Diabetes Res Clin Pract. 2007; 75(3): 339-47

15. Letassy N, Dennis V, Lyons TJ, Harrison D, Burton M, Kirkpatrick A. Know your diabetes risk project: Student pharmacists educating adults about diabetes risk in a community pharmacy setting. J Am Pharm Assoc. 2009; 50(2): 188-94.

16. Monte SV, Slazak EM, Albanese NP, Adelman M, Rao G, Paladino JA. Clinical and economic impact of a diabetes clinical pharmacy service program in a university and primary care-based collaboration model. J Am Pharm Assoc. 2009; 49(2): 200-8.

17. Shane-McWhorter L, Armor B, Johnson JT, Letassy N, Reichert SL, Sisson EM, et al. Pharmacist Scope of Practice, Standards of Practice, and Standards of Professional Performance for Diabetes Educators. Diabetes Educ. 2009; 35(3 suppl): 69S-84S.

18. Republic Scientific Committee for Clinical Guidelines development and implementation, Ministry of Health Republic of Serbia. National Clinical Guidelines for Diabetes Mellitus diagnosis and prevention. The second revised edition; 2012 (in Serbian) [cited 2013 Dec 20]. Available from: URL: http://www.zdravlje.gov.rs/downloads/2013/Januar/ SiraVerzijaVodicaZaDijagnostikovanjelLecenjeDiabetesMellitusa.pdf

19. Republic Scientific Committee for Clinical Guidelines development and implementation, Ministry of Health Republic of Serbia, Serbian Medical Association. National Guidelines for Doctors in the Primary Health CarePrevention of type 2 diabetes; 2005 (in Serbian) [cited 2013 Aug 21]. Available from: URL: http://www.zdravlje.gov.rs/downloads/2008/Sa\%20 Zdravlja/dokumenta/Vodici/prevencija\%20dijabetesa\%20tip\%202.pdf

20. Ministry of Health Republic of Serbia. National programme of early detection and prevention of type 2 diabetes; 2009 (in Serbian) [cited 2013 Dec 15]. Available from: URL http://www.zdravlje.gov.rs/downloads/Zakoni/Strategije/ Nacionalni\%20Program\%20Prevencije\%20I\%20Rane\%20Detekcije\%20 Tiba\%20Dva\%20Dijabetesa.pdf

21. Santschi V, Chiolero A, Burnand B, Colosimo AL, Paradis G. Impact of pharmacist care in the management of cardiovascular disease risk factors: a systematic review and meta-analysis of randomized trials. Arch Intern Med. 2011; 171(16): 1441-53.

22. Medical Research Council (MRC). Developing and evaluating complex interventions: new guidance; 2006 [cited 2014 Feb 8]. Available from: URL: http://www.mrc.ac.uk/documents/pdf/complex-interventions-guidance/

23. Correr CJ, Melchiors AC, de Souza TT, Rotta I, Salgado TM, Fernandez-Llimos F. A tool to characterize the components of pharmacist interventions in clinical pharmacy services: the DEPICT project. Ann Pharmacother. 2013; 47(7-8): 946-52.

24. National Center for Chronic Disease Prevention and Health Promotion. A PROGRAM GUIDE FOR PUBLIC HEALTH Partnering with Pharmacists in the Prevention and Control of Chronic Diseases; 2012 [cited 2013 Aug 21]. Available from: URL: http://www.cdc.gov/dhdsp/programs/spha/docs/ pharmacist_guide.pdf

25. Pope C, Ziebland S, Mays N. Analysing qualitative data. In: Pope C, Mays N. Qualitative Research in Health Care. Third Edition. Oxford, United Kingdom: Blackwell Publishing Ltd; 2007. 63-81.

26. Antonić R, Jovanović M, Golubovic B, Vučićević K, Ćulafić M, Miljković B et al. Investigation of the impact of pharmaceutical care on improvement of treatment knowledge and inhalation technique in asthma patients. Arh Pharm. 2013; 63(5): 419-30.

27. Kocic VP, T.asic L.j, Mitic DS. Pharmacist in Serbia in prevention of diabetes and pubic health. Paper presented at the 68th International Pharmaceutical Federation Congress; Basel, Switzerland; 2008 Aug 29-Sep 4.

28. Kocic VP, Basaric D., Tasic Lj. Counseling on Obesity in Community Pharmacies. Paper presented at the Conference on Pharmacists and Patient Safety; Riga, Latvia; 2005.

29. Pharmakon. Evidence Report 10 Opportunistic screenings in primary care 2010. Frøkjær B. Denmark: Pharmakon; 2010 [ cited 2014 Feb 25 ]. Available from: URL: http://europharm.pbworks.com/f/Evidence+report+10+ UK++2006.pdf

30. Krass I, Delaney C, Glaubitz S, Kanjanarach T. Measuring patient satisfaction with diabetes disease state management services in community pharmacy. Res Social Adm Pharm. 2009; 5(1): 31-9.

31. Charrois TL, Durec T, Tsuyuki RT. Systematic reviews of pharmacy practice research: methodologic issues in searching, evaluating, interpreting, and disseminating results. Ann Pharmacother. 2009; 43(1): 118-22.

32. Balázs H. Hungarian Diabetes Report [online]. 2007 [ cited 2014 Feb 14 ]. Available from: URL: http://www.europharmforum.org/file/8034

33. Talbot P, Dunbar M. Nova Scotia Prediabetes Project: upstream screening and community intervention for prediabetes and undiagnosed type 2 diabetes. Chronic Dis Inj Can. 2011; 32(1): 2-11.

34. Goyder E, Wild S, Fischbacher C, Carlisle J, Peters J. Evaluating the impact of a national pilot screening programme for type 2 diabetes in deprived areas of England. Fam Pract. 2008; 25(5): 370-5.

35. Rose $G$. The relation of risk to exposure. In: Rose $G$. The strategy of preventive medicine. Oxford, United Kingdom: Oxford University Press; 1992.

36. Pongwecharak J, Treeranurat T. Lifestyle changes for prehypertension with other cardiovascular risk factors: Findings from Thailand. J Am Pharm Assoc. 2011; 51(6): 719-26.

37. Müller U, Hämmerlein A, Casper A, Schulz M. Community pharmacy-based intervention to improve self-monitoring of blood glucose in type 2 diabetic patien. Pharm Pract (Granada). 2006; 4(4): 195-203.

38. Worswick J, Wayne SC, Bennett R, Fiander M, Mayhew A, Weir MC, et al. Improving quality of care for persons with diabetes: an overview of systematic reviews-what does the evidence tell us? Syst Rev. 2013; 2: 26.

39. Weinberger M, Oddone EZ, Henderson WG, Smith DM, Huey J, Giobbie-Hurder A, et al. Multisite randomized controlled trials in health services research: scientific challenges and operational issues. Med Care. 2001; 39(6): 627-34.

40. Olenak JL, Calpin M. Establishing a cardiovascular health and wellness program in a community pharmacy: screening for metabolic syndrome. J Am Pharm Assoc. 2009; 50(1): 32-6. 